\title{
OPTIMIZATION OF COMPONENT VARIABLES BY STATISTICAL APPROACH FOR DESIGN OF CHRONOTHERAPEUTIC DOSAGE FORM FOR HYPERTENSION
}

\author{
SHAILESH SHARMA ${ }^{1}$, NIMRATA SETH ${ }^{2,3 *}$ \\ ${ }^{1}$ Department of Pharmaceutical Research, ASBASJSM College of Pharmacy, Bela, Punjab, India. ${ }^{2}$ Department of Pharmaceutics, Rayat \\ Institute of Pharmacy, Railmajra, Punjab, India. ${ }^{3}$ Department of Research and Development, Inder Kumar Gujral, Punjab Technical \\ University, Kapurthala, Punjab, India. Email: nimrata.bela@gmail.com
}

Received: 14 December 2018, Revised and Accepted: 08 February 2019

ABSTRACT

Objective: Blood pressure (BP) pursues circadian rhythms projecting its highest values during early morning and lowest during night. The aim of the present investigation was to design a newer programmable chronotherapy based capsule system containing delayed release microspheres of losartan potassium for effective management of hypertension.

Methods: First, the microspheres were prepared with Eudragit RS100 by optimization technique through the application of Design Expert ${ }^{\circledR}$ software. The optimized microsphere formulation was filled in a capsule shell, and these shells were coated with 10\% w/v Eudragit L100:Eudragit S100 (in ratio 1:2), in isopropyl alcohol: water as solvent system, to provide the necessary delay in emptying of capsule content. The whole capsular system was evaluated by various characteristic formulation parameters. Validation of optimization model and statistical interpretation of results was done using analysis of variance.

Results: The results indicated that the optimized triple coated capsule shells showed an extended release of drug from microspheres after a lag time of $4 \mathrm{~h}$.

Conclusion: Conclusively, the chronotherapeutic system of losartan potassium was successfully developed to be dosed at bedtime that could benefit from the known circadian rhythms of the disease to control the BP for once a day therapy.

Keywords: Statistical design approach, Eudragit, Chronotherapy, Coated capsule system, Losartan potassium.

(c) 2019 The Authors. Published by Innovare Academic Sciences Pvt Ltd. This is an open access article under the CC BY license (http://creativecommons. org/licenses/by/4. 0/) DOI: http://dx.doi.org/10.22159/ajpcr.2019.v12i4.31334

\section{INTRODUCTION}

In the body, many physiological functions are regulated by transient release of bioactive principles at a specific time. Hence, to mimic the functions of living organisms, advances in research are aiming toward synchronizing the drug delivery in a manner consistent with the body's circadian rhythms to bring both commercial and therapeutic value to health care. The last decade has witnessed the emergence of chronotherapeutic drug delivery system for several diseases. Large data-based analysis and epidemiological studies have demonstrated that many cardiovascular events such as myocardial infarction, stroke, and sudden cardiac death cluster during early morning at around 6 am and then at 12 noon. It has been attributed to the fact that there are marked circadian rhythms in blood pressure (BP) that accounts for a sharp rise in BP during early morning and then in the afternoon; after that, BP declines during night time falling $15-20 \mathrm{~mm} \mathrm{Hg}$ between 8:00 pm and 2:00 am. This rise in BP is mainly ascribed to enhanced plasma-renin activity [1-3]. Thus, one of the newest advances in antihypertensive therapy is the design of drugs according to the chronotherapy that would deliver the drug in highest concentrations at the time of maximum need (in early morning hours) after an initial lag phase characterized by a period of no drug release.

Thus, the aim of the present investigation is to design a delayed release multiparticulate chronotherapeutic capsular drug delivery system containing losartan potassium microspheres. Losartan potassium is an angiotensin receptor blocker that works by antagonizing the renninangiotensin-aldosterone system; later being one of the contributing factors for the marked rise in early morning BP. Hence, an attempt has been made to develop a newer dosage form of losartan potassium to be dosed at bedtime and release the drug after a lag time of $2 \mathrm{~h}$. Moreover, losartan potassium tends to remain lesser solubilized in simulated gastric fluid (SGF) pH 1.2 that accounts for its low absorption while its solubility increases in SIF pH6.8. The drug would be released in SIF pH 6.8 in a controlled manner; thereby, plasma drug levels would rise during the early morning when BP is at its highest (as administration of dosage form is not feasible so early); thus, preventing the major cardiovascular events [4-7]. Hence, the system could benefit from the known circadian rhythms of the disease to control the BP for once a day therapy and overcome shortcomings of the currently available typical conventional and controlled release formulations.

The microspheres of losartan potassium were prepared using polymethacrylate polymer, Eudragit RS100, by emulsion solvent evaporation method through the application of statistical design approach. Eudragit RS100 is being increasingly employed for the development of oral sustained release microspheres [8,9]. It is a low permeability neutral polymer that is insoluble in water and digestive juices but swells due to the presence of quaternary ammonium groups; thus, releases the drug by diffusion [10]. The optimized microsphere formulation was filled into hard gelatin capsule shells. To synchronize the drug release with the circadian rhythms for hypertension, the shell was coated with Eudragit L100 [11] to obtain the desired lag time based on preliminary trials conducted to optimize the ratio.

\section{MATERIALS AND METHODS}

Materials

Losartan potassium was obtained as a gift sample from Theon Pharmaceuticals Pvt., Ltd., Baddi. Eudragit RS 100, L100 was procured from Theon Pharmaceuticals Pvt., Ltd., Baddi. Isopropyl alcohol, Light liquid paraffin, $\mathrm{n}$-hexane, methanol, and dichloromethane were obtained 
from Loba Chemicals Pvt., Ltd. PEG 6000, Talc, Span 80, potassium dihydrogen orthophosphate, sodium hydroxide, and concentrated hydrochloric acid were purchased from S. D. Fine Chemicals.

\section{Methods}

Preparation of microspheres: Statistical design approach

Statistical experimental designs are powerful and systematic tools in multiple factor optimizations in fewer experimental trials. Hence, for preparation of microspheres, response surface methodology employing central composite design (CCD) was applied. The microspheres of Losartan potassium were prepared by varying the drug: polymer ratio and codissolving them at room temperature into a mixture methanolacetone $(1: 1 \mathrm{v} / \mathrm{v})$ with continuous stirring using Remi's mechanical stirrer (model: RQ - 121/D). The drug: polymer ratio and stirring speed were varied as per the CCD experimental design as shown in Table 1. The resultant dispersion was slowly introduced into light liquid paraffin containing span $80(1 \% \mathrm{w} / \mathrm{w})$ as an emulsifying agent. Light liquid paraffin was then decanted, and the microspheres were separated by filtration followed by washings with n-hexane to remove paraffin. The resulting microspheres were dried at room temperature for $24 \mathrm{~h}$ and evaluated for various in vitro parameters [12-14].

\section{Optimization and validation model}

To optimize the formulation variables, factors selected for study were drug: polymer ratio (A) and stirring speed (B) taken at five different levels, namely - alpha, low, center point, high level, and +alpha level. Diverse batches of losartan potassium loaded Eudragit microparticles were prepared as per the CCD, and a total of 13 runs were presented by the Design Expert ${ }^{\circledR}$ software [15-18]. The response or dependent variables studied were mean particle size (Y1), drug entrapment efficiency (Y2), percent yield (Y3), and drug release at $8^{\text {th }} \mathrm{h}(\mathrm{Y} 4)$. The design matrix along with the investigated response variables is shown in Table 1. Experimental findings were analyzed using analysis of variance (ANOVA) by fitting the response figures in the run design.

The response (Yi) in each testing run was calculated by carrying out a regression analysis to develop equations for dependent variables (Y1-Y4).

$Y i=\beta_{0}+\beta_{1} A+\beta_{2} B+\beta_{3} A B+\beta_{4} A^{2}+\beta_{5} B^{2}$

Where, $\mathrm{Y}$ is estimated response of dependent variables,

$\beta_{0}$ is the intercept of the polynomial equation,

$\beta_{1-5}$ represents estimated regression coefficient for factor A and B
$\mathrm{AB}$ are the coefficients corresponding interaction and $A^{2}$ and $B^{2}$ represent the quadratic effects.

ANOVA was also used to obtain the F-values, p-values, and multiple correlation coefficients $\left(\mathrm{R}^{2}\right)$; adjusted and predicted $\mathrm{R}^{2}$, lack of fit and PRESS value for authenticating the suitability of models. Exhaustive matrix seeks over the experimental domain was performed to find out the solutions and then checkpoint formulations were selected to assess the optimization capability of the model generated through CCD $[19,20]$. The experimentally obtained results were then compared with the predicted responses obtained from the equations of the model and residuals were calculated.

\section{Evaluation of microparticles}

Microparticles were evaluated for micromeritic properties by measuring the angle of repose, bulk density, tapped density, Carr's index, and Hausner ratio using standard reported procedures [21]. The average particle size of microspheres was analyzed by simple optical microscopy method using the ocular lens and stage micrometer. Approximately 300 microspheres were counted and the average equivalent spherical diameter was measured [22-25]. The drug entrapment efficiency was determined by taking accurately weighed microspheres equivalent to $25 \mathrm{mg}$ of losartan potassium and crushed to obtain a fine powder. The powder was dissolved in $100 \mathrm{ml}$ of phosphate buffer $\mathrm{pH} 6.8$ in a conical flask. The solution obtained was filtered, suitably diluted and analyzed spectrophotometrically using ultraviolet-visible (UV-VIS) double beam spectrophotometer at $235 \mathrm{~nm}$. All the readings were taken in triplicate. Drug content was determined by the following formula:

$$
\text { Drug Entrapment Efficiency }(\%)=\frac{\begin{array}{l}
\text { Conc.of drug presentin } \\
\text { microparticles }
\end{array}}{\text { Amount of Drug initiallyTaken }} \times 100
$$

The microspheres obtained were weighed accurately, and the percentage yield was calculated as the weight of losartan potassium microspheres recovered from each batch in relation to the sum of starting material $[26,27]$.

Yield $(\%)=\frac{\text { Actual weight of themicrospheresobtained }}{\text { Total weight of the excipientsanddrug }} \times 100$ Eq. (A.3)

\begin{tabular}{|c|c|c|c|c|c|c|}
\hline \multirow[t]{2}{*}{ Runs } & \multicolumn{2}{|l|}{ Independent variables } & \multicolumn{4}{|c|}{ Dependent variables } \\
\hline & Drug: polymer Ratio (A), w/w & Stirring Speed (B), rpm & $\begin{array}{l}\text { Mean particle } \\
\text { size (Y1), } \mu \mathrm{m}\end{array}$ & $\begin{array}{l}\text { Entrapment } \\
\text { efficiency (Y2), \% }\end{array}$ & $\begin{array}{l}\text { Percent yield } \\
\text { (Y3), \% }\end{array}$ & $\begin{array}{l}\text { Drug release at } 8^{\text {th }} h \\
\text { (Y4), \% }\end{array}$ \\
\hline 1. & 1 & -1 & $169.2 \pm 1.23$ & $71.37 \pm 1.23$ & $65.49 \pm 0.74$ & $67.96 \pm 2.62$ \\
\hline 2. & 0 & 0 & $121.26 \pm 2.38$ & $79.73 \pm 1.09$ & $76.49 \pm 1.73$ & $76.55 \pm 1.29$ \\
\hline 3. & -1 & 1 & $102.28 \pm 2.03$ & $70.39 \pm 1.54$ & $75.15 \pm 2.47$ & $75.94 \pm 0.47$ \\
\hline 4. & 1 & 1 & $140.66 \pm 0.86$ & $74.18 \pm 1.25$ & $74.59 \pm 1.74$ & $74.69 \pm 1.20$ \\
\hline 6. & -1 & -1 & $119.69 \pm 1.03$ & $69.3 \pm 2.26$ & $77.98 \pm 1.74$ & $76.68 \pm 0.82$ \\
\hline 7. & 0 & -1.41421 & $145.69 \pm 0.36$ & $73.05 \pm 0.63$ & $70.26 \pm 1.23$ & $64.19 \pm 2.95$ \\
\hline 8. & -1.41421 & 0 & $100.96 \pm 1.47$ & $67.95 \pm 1.78$ & $76.85 \pm 2.05$ & $77.19 \pm 2.40$ \\
\hline 9. & 1.41421 & 0 & $163.79 \pm 1.59$ & $73.67 \pm 1.78$ & $67.95 \pm 0.86$ & $73.89 \pm 1.23$ \\
\hline 10. & 0 & 0 & $120.03 \pm 1.15$ & $79.1 \pm 0.83$ & $67.45 \pm 0.55$ & $80.64 \pm 2.29$ \\
\hline 11. & 0 & 0 & $119.49 \pm 1.33$ & $80.74 \pm 1.02$ & $69.64 \pm 1.32$ & $66.55 \pm 3.54$ \\
\hline 12. & 0 & 0 & $120.55 \pm 0.38$ & $78.88 \pm 1.90$ & $65.29 \pm 1.96$ & $80.95 \pm 2.78$ \\
\hline 13. & 0 & 1.41421 & $113.68 \pm 2.59$ & $75.96 \pm 2.44$ & $62.56 \pm 1.08$ & $79.25 \pm 1.40$ \\
\hline $\begin{array}{l}\text { S. } \\
\text { No. }\end{array}$ & Independent variables & $(-1.41421)$ alpha level & $-1($ low) & 0 (middle) & 1 (high) & $(+1.41421)$ alpha level \\
\hline 1. & Drug: polymer ratio $(\mathrm{w} / \mathrm{w}), \mathrm{A}$ & 1.58 & $1: 2$ & $1: 3$ & $1: 4$ & 4.41 \\
\hline 2. & Stirring speed (rpm), B & 717 & 800 & 1000 & 1200 & 1282 \\
\hline
\end{tabular}

Table 1: Central composite design matrix, the observed responses, and actual or coded values 
On the basis of the optimization and validation model, the optimized formulation was selected for further analysis. Fourier-transform infrared (FTIR) spectra of pure drug and optimized formulation were recorded using attenuated total reflection-FTIR spectrophotometer to investigate any possible interaction between drug-loaded microspheres. The morphology of optimized formulation of microspheres was examined by scanning electron microscope (SEM) analysis using SEM; Jeol JSM-6400, Japan. To analyze the existence condition of LP in the microspheres, digital signature certificate (DSC) of the LP, LP microspheres were carried out.

In vitro drug release study was carried out in simulated physiological $\mathrm{pH} 6.8$ using USP Type I dissolution apparatus at $37 \pm 0.5^{\circ} \mathrm{C}$ to calculate the amount of drug released from microspheres. The assembly was operated at $100 \mathrm{rpm}$ under sink conditions thereby maintaining the constant dissolution volume of $900 \mathrm{ml}$. The sample was withdrawn at suitable time intervals and replaced with fresh equal volume of dissolution medium. The samples withdrawn were analyzed using double beam UV-VIS spectrophotometer at $235 \mathrm{~nm}$ to determine the percent drug released. The dissolution data so obtained were fitted to various drug-release kinetic models such as zero-order, first-order, Higuchi, and Korsmeyer-Peppas model. The release kinetics was assessed by comparing the values of the regression coefficient $\left(\mathrm{r}^{2}\right)[28,29]$.

\section{Filling of capsule shell with optimized microparticle formulation}

After optimization of coating, the uncoated capsule bodies were taken and filled with optimized microsphere formulation equivalent to $25 \mathrm{mg}$ of losartan potassium. The capsule was sealed by fixing the cap of shell over capsule body.

\section{Coating of filled capsule shell}

The whole capsule system containing optimized microparticle formulation was optimally coated with plasticized $10 \% \mathrm{w} / \mathrm{v}$ Eudragit L100 in isopropyl alcohol: water plasticized with 10\% PEG 6000 containing talc as a glidant. The coating was done by dip coating method, and the number of coatings was varied from 1 to 4 to attain $8-10 \%$ weight gain [11,30-33]. The design scheme for the development of capsule-based chronotherapeutic system has been shown in Fig. 1.

\section{Evaluation of coated capsule shells containing optimized formulation}

Ten capsules were selected randomly; thickness of uncoated and coated capsules was measured using digital screw gauge. Coating thickness was determined by measuring the difference between thicknesses before and after coating. The time taken by the coating to dissolve as indicated by the bursting of capsule shell was reported as lag time and evaluated using dissolution test apparatus for first $2 \mathrm{~h}$ in SGF pH 1.2 and SIF pH 6.8 for remaining time. A dissolution study was carried out using USP type I apparatus. Coated capsules were immersed in $900 \mathrm{ml}$ of SGF pH 1.2 maintained at $37 \pm 0.5^{\circ} \mathrm{C}$. Dissolution was carried out for $2 \mathrm{~h}$ at $100 \mathrm{rpm}$ and then shifted to $\mathrm{pH} 6.8$ medium by adding concentrated high $\mathrm{pH}$ media in the same vessel. This $\mathrm{pH}$ shift simulated the transition from stomach to intestines for remaining dissolution testing until $10 \mathrm{~h}$ [34]. Aliquots of $5 \mathrm{ml}$ were withdrawn at suitable time intervals from the dissolution assembly and replaced with an equal amount of fresh buffer. The samples taken were analyzed at $235 \mathrm{~nm}$ spectrophotometrically and percent drug released was calculated.

\section{RESULTS}

Formulation optimization of microparticles of losartan potassium For the preparation of microcapsules, emulsion solvent evaporation was employed using a mixed solvent system (methanol-acetone) as the dispersed phase and light liquid paraffin as an immiscible continuous phase stabilized with span 80 as an emulsifier. Judicial selection of solvent system was done based on their dielectric constants. The solvents having dielectric constant above 10 and below 40 reflect poor miscibility in light liquid paraffin; therefore, paraffin was preferred as a continuous phase in which both losartan potassium and Eudragit RS100 are scantily soluble [35]. 13 formulations were designed by applying CCD to optimize the composition and process variables.

\section{Statistical data analysis and model validation}

Models for different responses were generated by means of Design Expert ${ }^{\circledR}$ software. The calculated values of the response variables are shown in Table 1. Linear, quadratic, cubic, and cross-product (2FI) models were generated by the software for the responses, and the fit summary has been represented in Table 2 .

The equations generated (Table 3) were used to quantify the response data and carried factors along with the coefficients. Positive sign of coefficient indicated synergistic effect (increase in response) while the negative sign indicated antagonistic effect (decrease in response values) as the factor was changed from low to high level [36]. The values of coefficients of linear equations indicated that the formulation variables had a controlling effect on the microsphere properties.

The ANOVA for the regression model demonstrated that the quadratic model was greatly significant as indicated by $p<0.0001$ and $R^{2}$ value as shown in Table 4.

\section{Mean particle size}

The values for mean particle size showed a broad variation ranging from $100.96 \pm 1.47$ to $169.20 \pm 1.23 \mu \mathrm{m}$. The data, as well as model, signified that the independent variables drug: polymer ratio (A) and stirring speed (B), their interaction term (AB) and the quadratic terms $\left(A^{2}\right.$ and $\left.B^{2}\right)$ showed a significant effect on particle size (Y1), $\mathrm{p}<0.0001$. Expanding the drug: polymer proportion brought about the mean microparticle size to move toward higher value, as indicated by the positive coefficients of $\mathrm{A}$. On the other hand, mean particle size decreased with increase in stirring speed as indicated by the negative coefficients of $\mathrm{B}, \mathrm{p}<0.0001$. It was observed that size decreased with increase in stirring speed and time up to a certain mid-level and then onward it remained constant or higher.

\section{Entrapment efficiency}

The values of drug entrapment efficiency (Y2) for the various experimental runs ranged between $67.95 \pm 1.78$ and $80.74 \pm 1.02 \%$. The

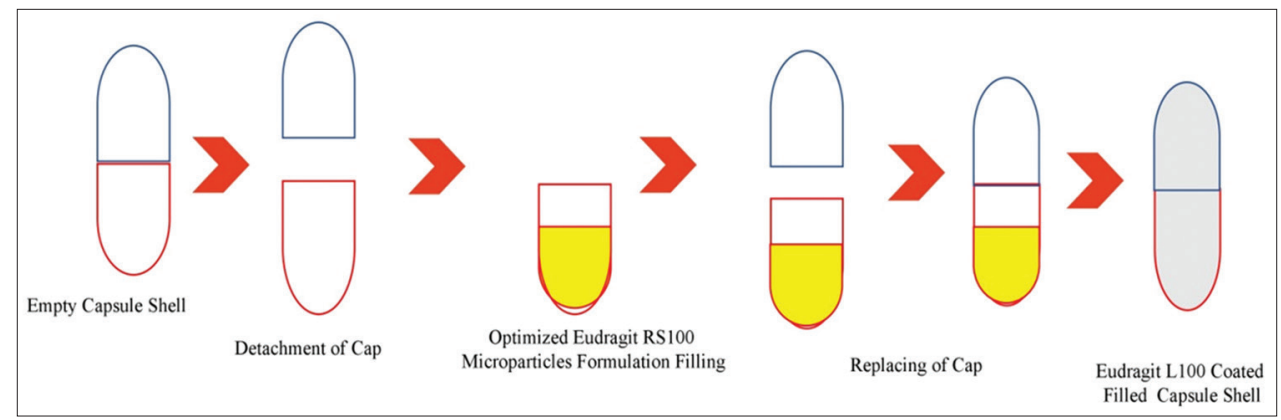

Fig. 1: Stages in the development of capsule-based chronotherapeutic system 
Table 2: Model summary statistics for dependent variables

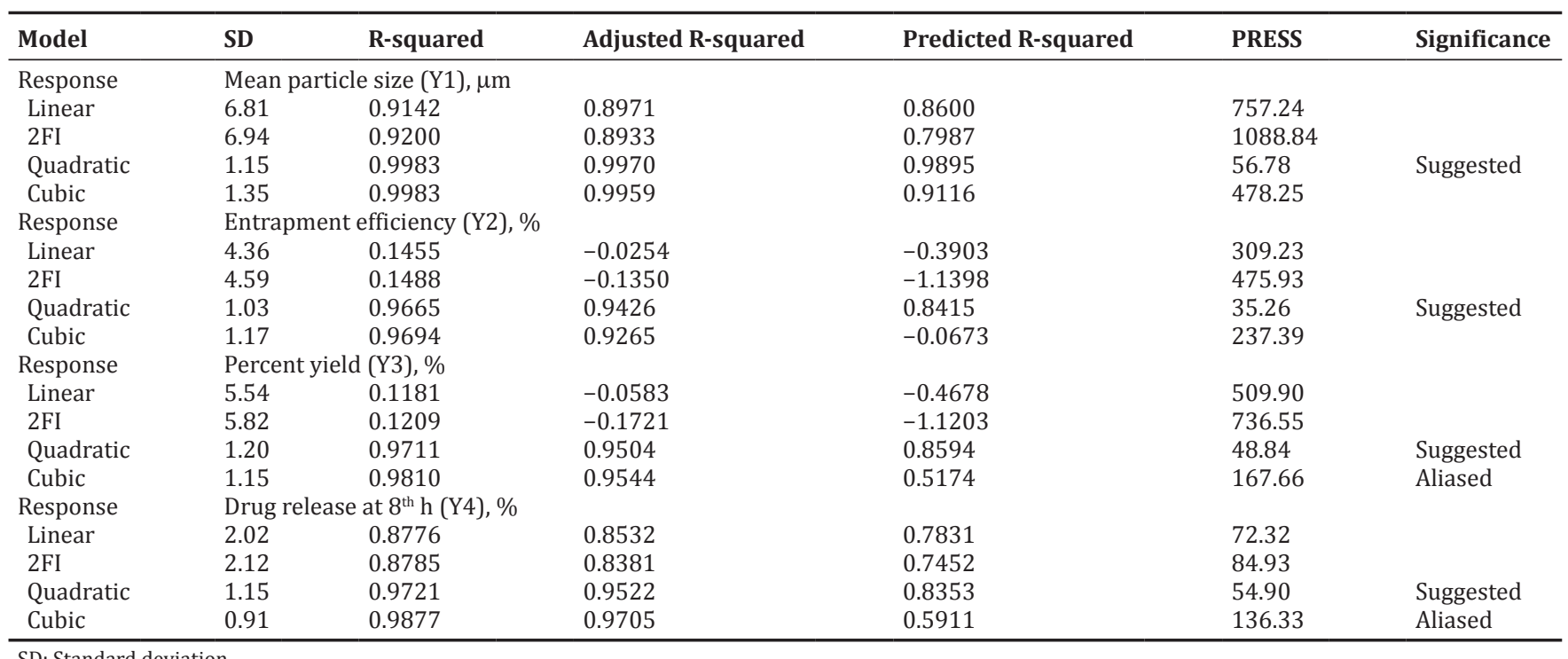

SD: Standard deviation

Table 3: Equations for quadratic model

\begin{tabular}{|c|c|c|c|c|c|c|}
\hline Response & Intercept & $\mathbf{A}$ & B & $\mathbf{A B}$ & $A^{\wedge} 2$ & $B^{\wedge} 2$ \\
\hline Mean particle size (Y1) & 120.362 & 22.0931 & -11.4024 & -2.7825 & 6.48837 & 5.14337 \\
\hline p value & & $<0.0001$ & $<0.0001$ & 0.0019 & $<0.0001$ & $<0.0001$ \\
\hline Entrapment efficiency (Y2) & 79.378 & 1.74366 & 1.00192 & 0.43 & -4.62087 & -2.77337 \\
\hline $\mathrm{p}$ value & & 0.0020 & 0.0286 & 0.4318 & $<0.0001$ & 0.0002 \\
\hline Percent yield (Y3) & 76.63 & 1.13 & 1.96 & 0.50 & -6.14 & -2.96 \\
\hline $\mathrm{p}$ value & & 0.0322 & 0.0024 & 0.4338 & $<0.0001$ & 0.0003 \\
\hline Drug release at $8^{\text {th }} h(Y 4)$ & 76.342 & -6.04726 & -0.0735786 & -0.275 & -2.056 & -0.771 \\
\hline
\end{tabular}

model showed that drug: polymer ratio (A) and stirring speed (B) had a positive effect on entrapment efficiency, $(p<0.0001)$. With the increase in independent variables, the entrapment efficiency increased to the middle level than it started decreasing on further increase in A and B.

\section{Percent yield}

The yield values for all the runs demonstrated wide difference going from a lowest of $62.56 \pm 1.08$ to highest of $77.98 \pm 1.74 \%$. The data indicated that percent yield was strongly dependent on the independent variable.

\section{In vitro drug release}

In vitro drug release data for all the experimental runs ranged between $64.19 \pm 2.62$ and $80.95 \pm 2.78 \%$.

\section{Validation by checkpoint formulation (CPF) and optimization} To approve the model equations resulting from regression analysis, four CPFs were selected randomly as recommended by the listing of solutions and CPFs were formulated. Table 5 shows the predicted and experimental values of both the responses and the value of residuals obtained.

Numerical optimization method was applied to arrive at the optimized formulation through the desirability function approach. With the view of keeping in mind to use the smallest size of dosage form, so as to incorporate in the capsule shell, the desirable levels of responses were constrained to mean particle size "in range," "maximum" percent yield and entrapment efficiency, and drug release at $8^{\text {th }} \mathrm{h}$ up to $80 \%$. On analyzing the various dependent variables and far-reaching assessment of practicality of exhaustive matrix seek, the accompanying blend of independent variables was recommended by the software with desirability function of 0.840 . The desirability plot for the optimized losartan potassium microparticles (OLMP) formulation has been shown in Fig. 2.

Batches of losartan potassium microspheres (OLPM) were developed using these optimum process variable settings and evaluated for responses. The results obtained for response variables were mean particle size of $112.41 \pm 1.27$, entrapment efficiency of $78.67 \pm 1.62 \%$, percent yield of $76.27 \%$, and drug rel at $8^{\text {th }} \mathrm{h}$ around $77.61 \pm 1.05 \%$ with an error value $<1$. To graphically envision the effect of formulation/ operation variables on the output variables, contour and response surface plot were constructed using the software as shown in Fig. 3.

Formulations of microspheres indicated that good flow properties as were observed from the various characteristics evaluation parameters. The values for angle of repose lied between $26.78^{\circ} \pm 0.64$ and $34.57^{\circ} \pm 0.36$, Carr's compressibility index for various formulations was in range $12.03-23.08 \%$ while the data obtained for Hausner ratio ranged between 1.14 and 1.30. The optimized formulation OLPM was selected for further experimental evaluation. The characteristic FTIR peaks of the drug were obtained at wave numbers $3197.48 \mathrm{~cm}^{-1}$ (O-Hstretching), $763.61 \mathrm{~cm}^{-1}$ (C-Clstretching), $1459.60 \mathrm{~cm}^{-1}$ (C=C stretching), $1577.61 \mathrm{~cm}^{-1}$ ( $\mathrm{C}=\mathrm{N}$ stretching), and $2956.14 \mathrm{~cm}^{-1}$ (C-H stretching). FTIR studies of optimized formulation showed that the drug was encapsulated in the microparticles. The spectrum of drug sample and microspheres has been shown in Fig. 4. SEM study revealed that the discrete, uniformly shaped spherical microspheres were obtained (Fig. 5). The DSC trace of LP showed a sharp thermographic peak at 279.8 and a broad endothermic peak at the same temperature as shown in Fig. 6.

In vitro drug release study for optimized formulation was carried out in phosphate buffer $\mathrm{pH} 6.8$ so as to mimic the physiological $\mathrm{pH}$. The 
Table 4: ANOVA responses for surface quadratic model

\begin{tabular}{|c|c|c|c|c|c|c|}
\hline Source & $\begin{array}{l}\text { Sum of } \\
\text { squares }\end{array}$ & Df & Mean square & F value & p-value Prob $>$ F & Significance \\
\hline \multicolumn{7}{|c|}{ Response for (Y1) mean particle size } \\
\hline Model & 5399.47 & 5 & 1079.89 & 810.11 & $<0.0001$ & \multirow[t]{6}{*}{ Significant } \\
\hline A-Drug: polymer ratio & 3904.85 & 1 & 3904.85 & 2929.31 & $<0.0001$ & \\
\hline B-Stirring speed & 1040.11 & 1 & 1040.11 & 780.26 & $<0.0001$ & \\
\hline $\mathrm{AB}$ & 30.97 & 1 & 30.97 & 23.23 & 0.0019 & \\
\hline $\mathrm{A} 2$ & 292.86 & 1 & 292.86 & 219.70 & $<0.0001$ & \\
\hline Residual & 9.33 & 7 & 1.33 & & & \\
\hline Lack of fit & 7.60 & 3 & 2.53 & 5.87 & 0.0601 & Not significant \\
\hline Pure error & 1.73 & 4 & 0.43 & & & \\
\hline Cor total & 5408.80 & 12 & & & & \\
\hline \multicolumn{7}{|c|}{ Response for (Y2) entrapment efficiency } \\
\hline Model & 214.98 & 5 & 43.00 & 40.44 & $<0.0001$ & \multirow[t]{6}{*}{ Significant } \\
\hline A-Drug: polymer ratio & 24.32 & 1 & 24.32 & 22.88 & 0.0020 & \\
\hline B-Stirring speed & 8.03 & 1 & 8.03 & 7.55 & 0.0286 & \\
\hline $\mathrm{A} 2$ & 148.54 & 1 & 148.54 & 139.71 & $<0.0001$ & \\
\hline B2 & 53.51 & 1 & 53.51 & 50.32 & 0.0002 & \\
\hline Residual & 7.44 & 7 & 1.06 & & & \\
\hline Lack of fit & 4.26 & 3 & 1.42 & 1.78 & 0.2894 & Not significant \\
\hline Pure error & 3.18 & 4 & 0.80 & & & \\
\hline Cor total & 222.42 & 12 & & & & \\
\hline \multicolumn{7}{|c|}{ Response for (Y3) percent yield } \\
\hline Model & 337.33 & 5 & 67.47 & 46.97 & $<0.0001$ & \multirow[t]{7}{*}{ Significant } \\
\hline A-drug: polymer ratio & 10.21 & 1 & 10.21 & 7.11 & 0.0322 & \\
\hline B-stirring speed & 30.81 & 1 & 30.81 & 21.45 & 0.0024 & \\
\hline $\mathrm{AB}$ & 0.99 & 1 & 0.99 & 0.69 & 0.4338 & \\
\hline $\mathrm{A} 2$ & 262.31 & 1 & 262.31 & 182.62 & $<0.0001$ & \\
\hline $\mathrm{B} 2$ & 60.98 & 1 & 60.98 & 42.45 & 0.0003 & \\
\hline Residual & 10.05 & 7 & 1.44 & & & \\
\hline Lack of fit & 5.97 & 3 & 1.99 & 1.95 & 0.2635 & Not significant \\
\hline Pure error & 4.08 & 4 & 1.02 & & & \\
\hline Cor total & 347.38 & 12 & & & & \\
\hline \multicolumn{7}{|c|}{ Response for (Y4) drug release at $8^{\text {th }} \mathrm{h}$} \\
\hline B-stirring speed & 0.043 & 1 & 0.043 & 0.033 & 0.8618 & \multirow{5}{*}{ Significant } \\
\hline $\mathrm{AB}$ & 0.30 & 1 & 0.30 & 0.23 & 0.6478 & \\
\hline $\mathrm{A} 2$ & 29.41 & 1 & 29.41 & 22.14 & 0.0022 & \\
\hline B2 & 4.14 & 1 & 4.14 & 3.11 & 0.1210 & \\
\hline Residual & 9.30 & 7 & 1.33 & & & \\
\hline Lack of fit & 7.28 & 3 & 2.43 & 4.80 & 0.0820 & Not significant \\
\hline Pure error & 2.02 & 4 & 0.51 & & & \\
\hline Cor total & 333.39 & 12 & & & & \\
\hline
\end{tabular}

ANOVA: Analysis of variance

Table 5: Validation of model with checkpoint formulations

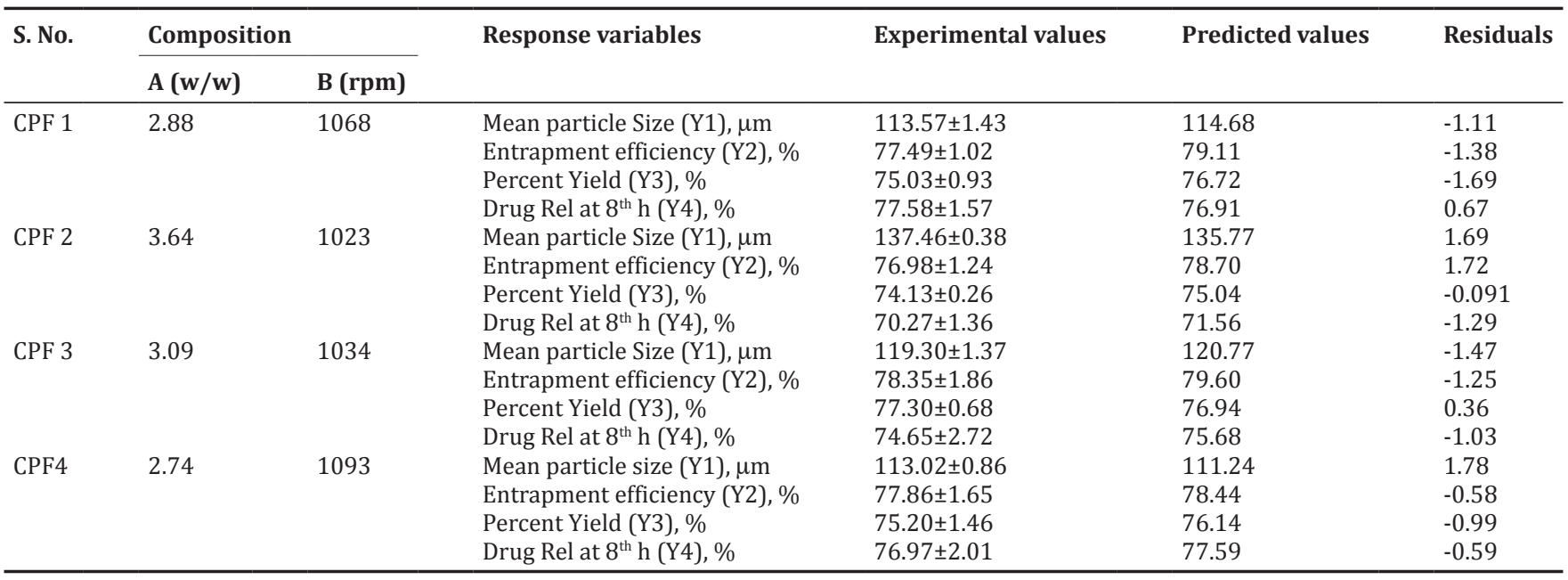




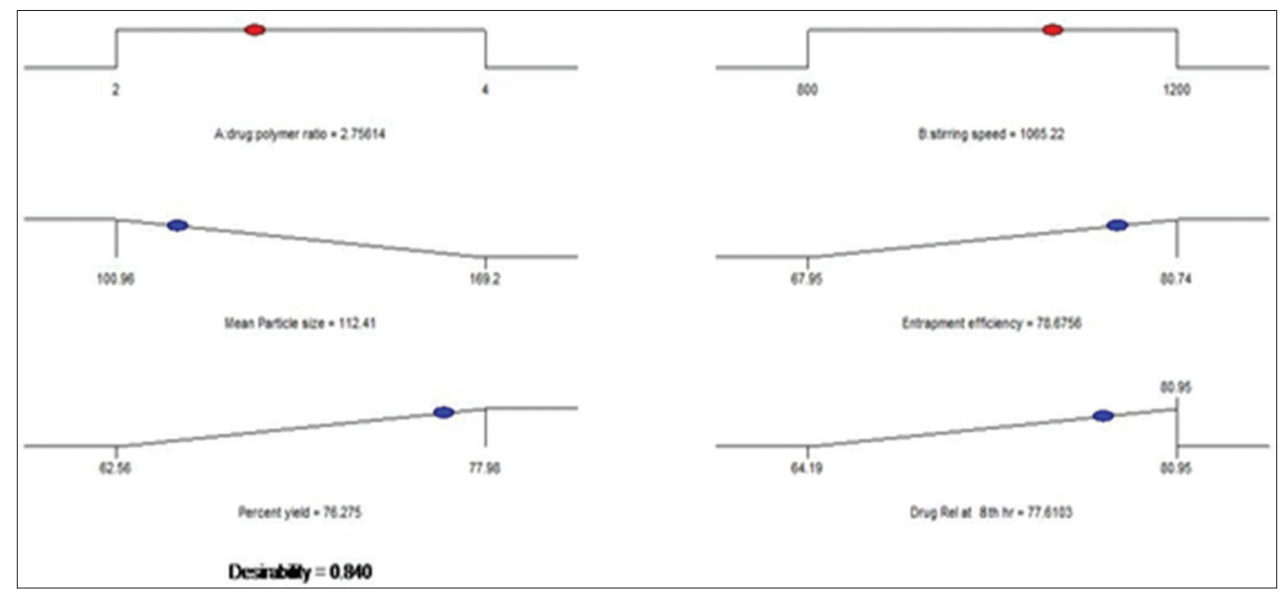

Fig. 2: Desirability plot for optimized formulation

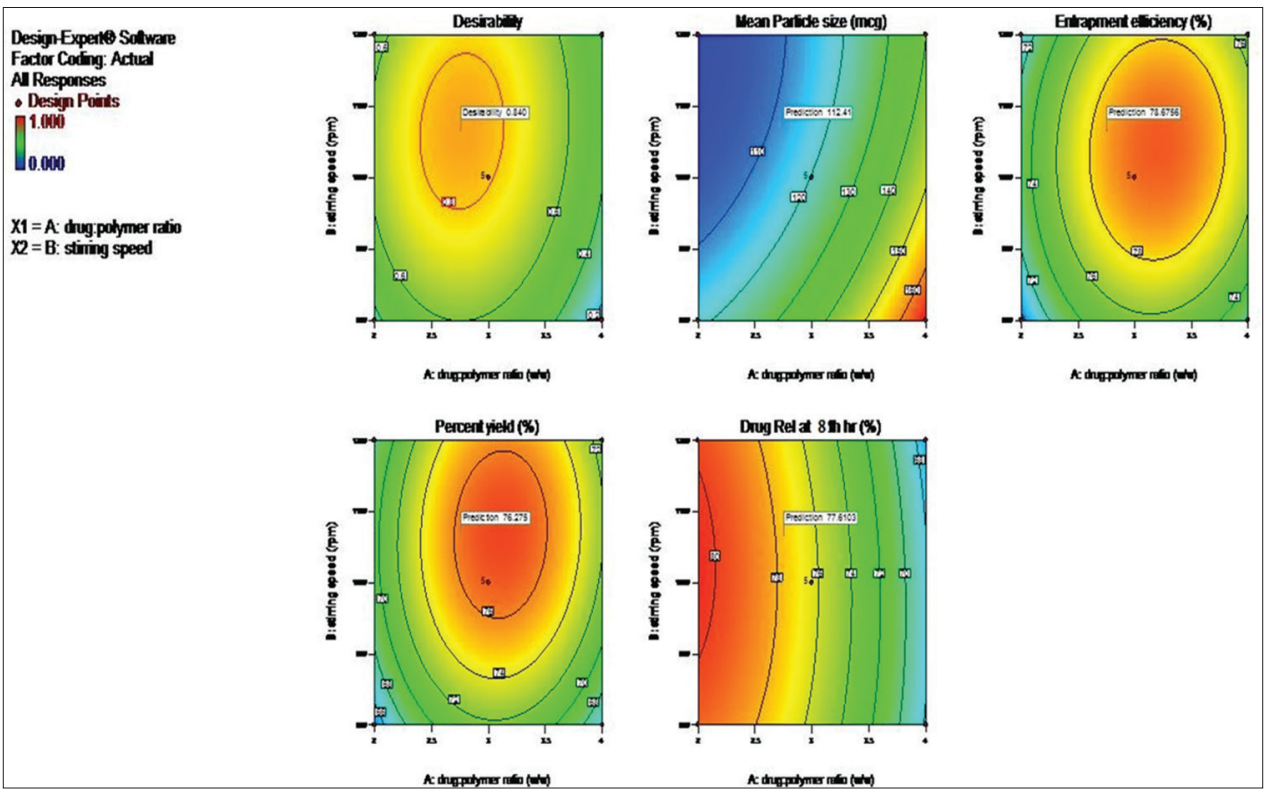

Fig. 3: Two-dimensional contour and three-dimensional response surface plot showing the effect of Independent variables (A and B) on response variables (Y1 - Y4)

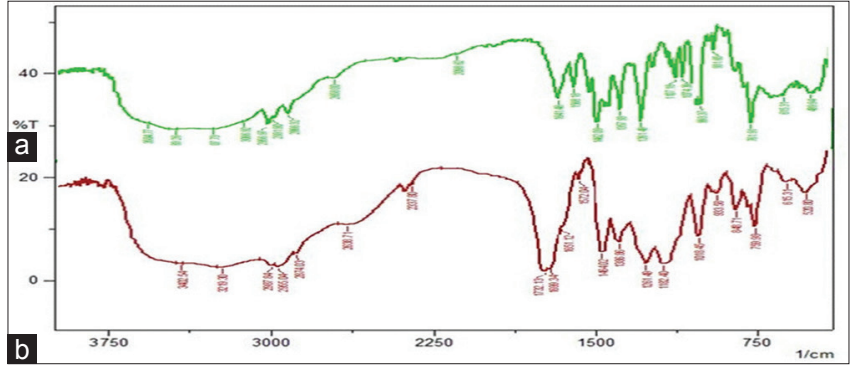

Fig. 4: Fourier-transform infraredspectra of (a) losartan potassium and (b) optimized microsphere formulation (OLPM) microparticles

optimized formulation showed maximum drug release of $78.36 \pm 1.05 \%$ in $8 \mathrm{~h}$. It was observed that as the drug: polymer ratio was increased that the drug release was sustained from the formulation. The dissolution data so obtained were then fitted to various drug-release kinetic models. The release mechanism was assessed by comparing the values of the regression coefficient $\left(\mathrm{r}^{2}\right)$. The value of the regression coefficient was found to be higher for Korsmeyer-Peppas and zero-order model, i.e. $\mathrm{r}^{2}=0.976$ and 0.980 , respectively.

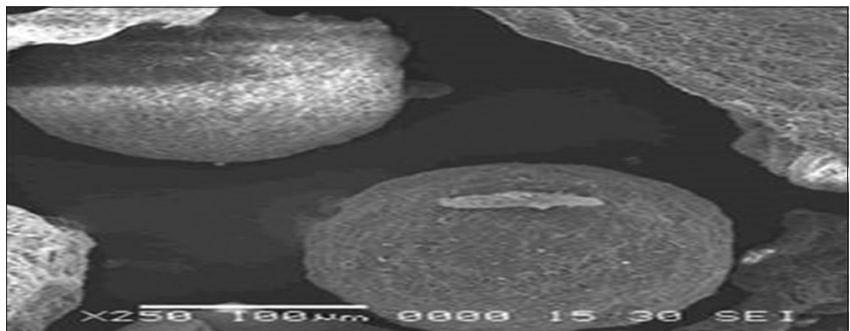

Fig. 5: Scanning electron microscope analysis of optimized microsphere formulation (OLPM) of losartan potassium

\section{Evaluation of filled coated capsule shells}

The coated capsules were found to be of uniform weight and thickness. The coating thickness for these ranged between 0.053 and $0.069 \pm$ $0.001 \mathrm{~mm}$. The in vitro drug release study was carried out in physiological buffers to analyze both lag time in drug release and in vitro dissolution data. A period of no drug release was observed for $2 \mathrm{~h}$ in SGF $\mathrm{pH} 1.2$ followed by the release of microspheres in the dissolution medium phosphate buffer $\mathrm{pH}$ 6.8. The dissolution study was carried out for a period of $12 \mathrm{~h}$, and prolonged release was observed from microspheres after a lag period of $2 \mathrm{~h}$. Comparative drug release profile from coated 
capsule shell containing OLPM aimed at stimulating chronotherapeutic release of the drug; matching the circadian rhythms and marketed formulation (Czartan - 25 mg capsule, Macleods Pharmaceuticals Ltd.) is shown in Fig. 7.

\section{DISCUSSION}

In the present study, the formulation design protocol was executed in three steps; first being the formulation optimization of microparticles

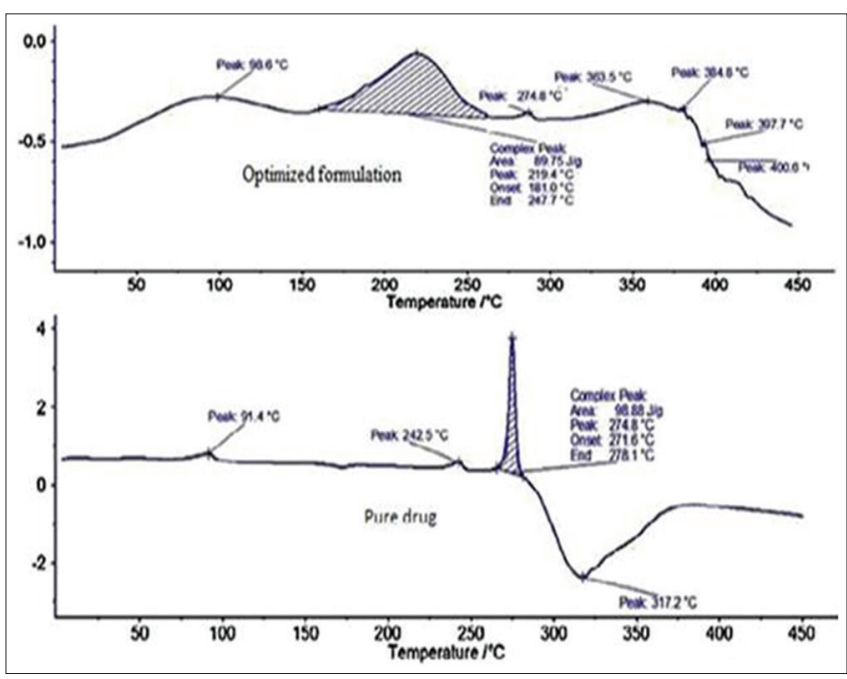

Fig. 6: Differential scanning calorimetric analysis of losartan potassium and optimized microsphere formulation (OLPM) of losartan potassium followed by its filling into the hard gelatin capsule shells. The last step consisted of applying a polymeric coating over the filled capsule shell to achieve the necessary lag time of around $2 \mathrm{~h}$.

Emulsion solvent evaporation was found reliable for preparation of microparticles of losartan potassium. Span 80 was supplemented as an emulsifier to prevent coalescence of droplets during solvent evaporation. The data generated by statistical experimental design clearly signified that the independent variables (A) and (B), their interaction term $(\mathrm{AB})$, and the quadratic terms $\left(\mathrm{A}^{2}\right.$ and $\left.\mathrm{B}^{2}\right)$ showed a significant effect on response variables (Y1-Y4); $(\mathrm{p}<0.0001)$. Higher polymer concentration produced more viscous dispersion, and therefore, shearing effect was less at impeded circulation that formed larger droplets [23,24]. Mean particle size decreased with increase in stirring speed producing uniform spherical microparticles while in case of entrapment efficiency (Y2), it was experiential that an increase in polymer concentration in a fixed volume of organic solvent resulted in augmenting the entrapment efficiency. In the case of percent yield (Y3), it was observed that finer particles formed during the preparation of microparticles tend to coalesce to give bigger particles with better percent yield. The model applied for drug release at $8^{\text {th }} \mathrm{h}(\mathrm{Y} 4)$ showed that the drug release retarded from the formulations as diffusional path length for drug release increased while with an increase in stirring speed the interfacial area per unit volume increased, so, the drug release also increased [19,37-40].

The reliability of the optimization model was further assessed by CPFs. The reasonably lower values of residual between predicted and observed experimental values for all the four response variables indicated a pragmatic agreement between the predicted and trial values. Hence, the mathematical model was well fitted. Numerical optimization technique using the desirability function approaching

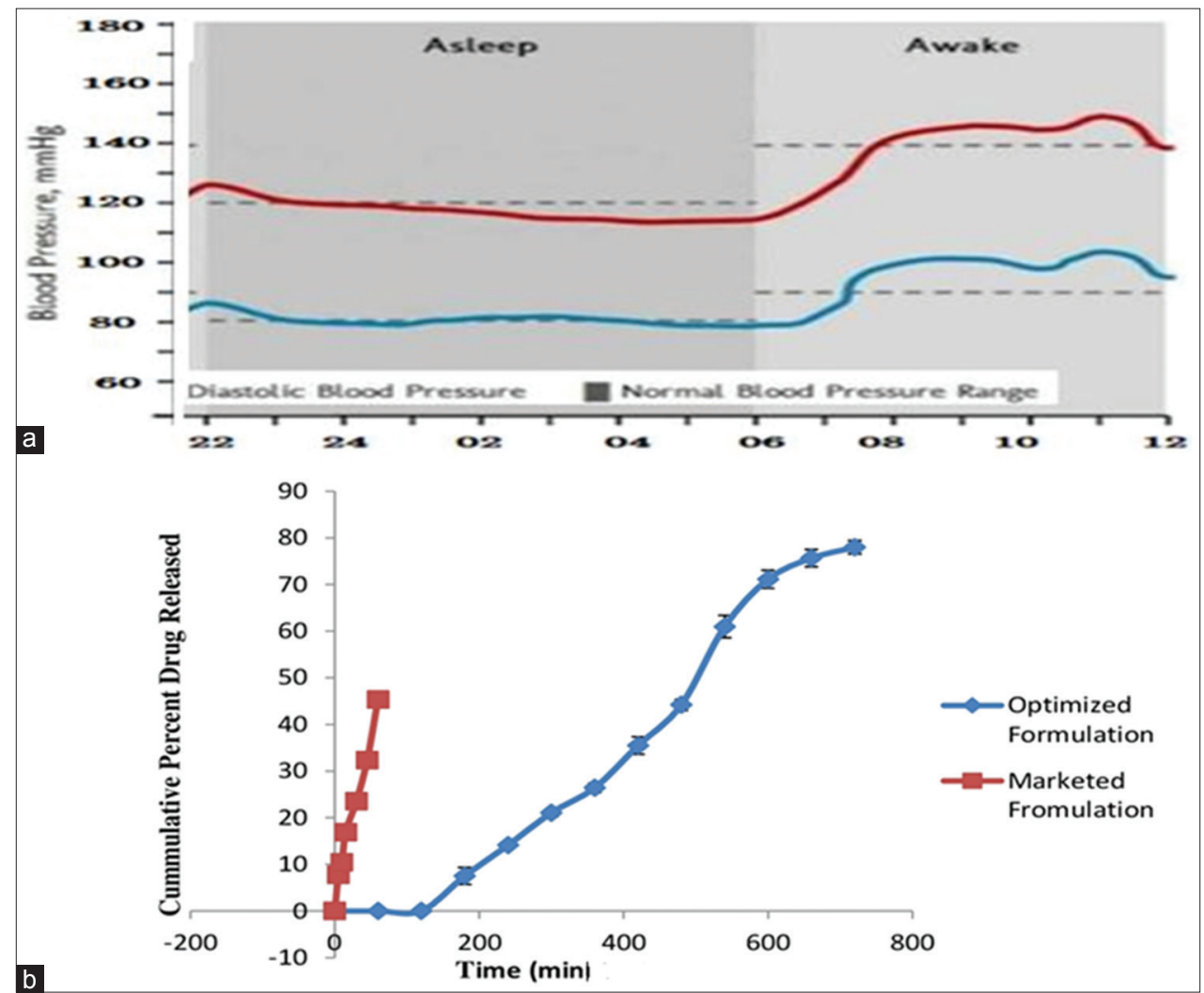

Fig. 7: Comparative drug release profile marketed formulation (Czartan) and coated capsule shell containing OLPM aimed at stimulating the chronotherapeutic release of the drug; matching the circadian rhythms. (a) Circadian variation in BP (Dip at night, surge in early morinng; Effective BP management demands chronotherapy based drug release system. (b) drug release pattern in-vitro from chronotherapy based capsule dosage from ; Designed for matching the circadium rhythms (Lower drug conc. at night and higher drug conc in morning) and marketed formulation releasing drug in $\mathrm{pH} 1.2$ 
1 for obtaining optimized formulation indicated desirable range for independent variables A and B to get an optimum response. From the contour and response surface plots, it was observed that increasing the drug: polymer ratio had a positive effect on all the response variables while with increase in stirring speed (B), (Y2), and (Y3) increased initially followed by decline or constancy state on further rise in both the independent parameters while drug release decreased.

FTIR studies of optimized formulation indicated the absence of undesirable chemical interaction between the drug and polymer. SEM study revealed that the discrete, uniformly shaped spherical microspheres were obtained. DSC results indicated that there is no change of LP in a pure state, formulation of microspheres. LP existed in an amorphous as a molecular dispersion in the polymeric matrix. In vitro drug liberation study for optimized formulation proposed a sustained release of drug from microparticles indicating the efficient applicability of Eudragit RS100 polymer in controlling the drug release of hydrophilic drugs.

Eudragit L100 was found to be optimum for delaying drug release. The inclusion of PEG 600 and talc further improvised the coating capability by enhancing coating adherence, integrity thus, providing flexible coating film with uniform thickness and smoothness after drying. Dissolution studies suggested that optimized Eudragit coating provided protection against emptying of capsule shell contents for a period of $2 \mathrm{~h}$ after which the coating dissolved exposing the capsule shell to a simulated physiological buffer that resulted in bursting of capsule shell thus releasing the formulation components followed by a sustained release of losartan potassium from Eudragit RS100 coated microspheres.

\section{CONCLUSION}

The capsule-based system designed for chronotherapeutic management of hypertension dealing with early morning pathology influenced by circadian rhythm was successfully prepared and optimized through a statistical experimental design approach.

\section{ACKNOWLEDGMENT}

The authors are grateful to Inder Kumar Gujral, Punjab Technical University, Jalandhar for providing the necessary platform for carrying out the research project.

\section{AUTHORS' CONTRIBUTIONS}

Study conception and design: Both Authors (Nimrata Seth and Dr. Shailesh Sharma). Experimental execution: Nimrata Seth. Analysis and interpretation of data: Both authors (Nimrata Seth and Dr. Shailesh Sharma). Drafting of the manuscript: Both authors (Nimrata Seth and Dr. Shailesh Sharma). Critical revision: Both authors (Nimrata Seth and Dr. Shailesh Sharma).

\section{CONFLICTS OF INTEREST}

No conflicts of interest associated with this work.

\section{REFERENCES}

1. Smith DH. Pharmacology of cardiovascular chronotherapeutic agents. Am J Hypertens 2001;14:296S-301S.

2. Prisant LM. Hypertension and chronotherapy: Shifting the treatment paradigm. Am J Hypertens 2001;14:277S-9S.

3. Hermida RC, Smolensky MH. Chronotherapy of hypertension. Curr Opin Nephrol Hypertens 2004;13:501-5.

4. Nayak UY, Shavi GV, Nayak Y, Averinen RK, Mutalik S, Reddy SM, et al. Chronotherapeutic drug delivery for early morning surge in blood pressure: A programmable delivery system. J Control Release 2009; 136:125-31.

5. Prisant LM, Weber M, Black HR. The role of circadian rhythm in cardiovascular function-efficacy of a chronotherapeutic approach to controlling hypertension with Verelan PM (verapamil HCL). Todays Ther Trend 2003;21:201-13.
6. Percel PJ, Vishnupad KS, Ventakesh GM. Timed Sustained Release Systems for Propranolol. Dublin, United States: Eurand Pharmaceuticals Limited; 2003.

7. Sica D, Frishman WH, Manowitz N. Pharmacokinetics of propranolol after single and multiple dosing with sustained release propranolol or propranolol CR (innopran XL), a new chronotherapeutic formulation. Heart Dis 2003;5:176-81.

8. Wu PC, Huang YB, Chang JS, Tsai MJ, Tsai YH. Design and evaluation of sustained release microspheres of potassium chloride prepared by Eudragit. Eur J Pharm Sci 2003;19:115-22.

9. Barzegar-Jalali M, Alaei-Beirami M, Javadzadeh Y. Comparison of physicochemical characteristics and drug release of diclofenac sodium Eudragit RS100 nanoparticles and solid dispersion. Powder Technol 2012;219:211-6.

10. Mehta KA, Kislaloglu MS, Phuapradit W. Release performance of poorly soluble drug from a novel Eudragit based multi-unit erosion matrix. Int J Pharm 2001;213:7-12.

11. Degussa Rohm Pharma Polymers, Enteric Coatings-pH control with Eudragit ${ }^{\circledR}$. Available from: http://www.chemistry.mdma.ch/hiveboard/ picproxie docs/000494861-xx4 1c Enteric Coatings pH control with_EUDRAGIT.pdf. [Last accessed on 2015 Dec 07]

12. Lee JH, Park TG, Choi HK. Effect of formulation and processing variables on the characteristics of microspheres for water soluble dugs prepared by w/o/o double emulsion solvent diffusion method. Int J Pharm 2000;196:75-83.

13. Phutane P, Shidhaye S, Lotlikar V, Ghule A, Sutar S, Kadam V, et al. In vitro evaluation of novel sustained release microspheres of glipizide prepared by the emulsion solvent diffusion-evaporation method. J Young Pharm 2010;2:35-41.

14. EL-Nahas HM. Optimization of Eudragit RS microspheres for controlled release of theophylline using response surface methodology. J Pharm Sci Res 2010;2 Suppl 10:663-71

15. Das SK, Yuvaraj K, Khanam J. Formulation development and statistical optimization of ibuprofen-loaded polymethacrylate microspheres using response surface methodology. Chem Eng Res Design 2015;96:1-14.

16. Chopra S, Patil GV, Motwani SK. Release modulating hydrophilic matrix systems of losartan potassium: Optimization of formulation using statistical experimental design. Eur J Pharm Biopharm 2007;66:73-82.

17. Kehoe S, Kilcup N, Boyd D. Evaluation of cytotoxicity for novel composite microspheres: Material optimization by response surface methodology. Matter Lett 2012;86:13-7.

18. Martins SA, Prazerers DM, Fonseca LP. Application of central composite design for DNA hybridization onto magnetic micropsheres. Anal Biochem 2009;391:17-23.

19. Deshmukh RK, Naik JB. The impact of preparation parameters on sustained release aceclofenac microspheres: A design of experiments. Adv Powder Tech 2015;26:244-52.

20. Myers RH, Montgomery DC, Anderson-Cook CM. Response Surface Methodology: Process and Product Optimization Using Designed Experiments. New Jersey, USA: John Wiley and Sons; 2009.

21. Milling EL. Microencapsulation. In: Lachman L, Lieberman HA, Kanig JL, editors. The Theory and Practice of Industrial Pharmacy. Mumbai: Varghese Publishing House; 1991. p. 26-7.

22. Sinko PJ. Martin's Physical Pharmacy \& Pharmaceutical Sciences. New Delhi: BI Publications Pvt., Ltd.; 2006.

23. Trivedi P, Verma AM, Garud N. Preparation and characterization of aceclofenac microspheres. Asian J Pharm 2008;2:110-5.

24. Tanwar YS, Naruka P, Ojha GR. Development and evaluation of microspheres of verapamil hydrochloride. Braz J Pharm Sci 2006;43: 529-34.

25. Srivastava AK, Ridhurkar DN, Wadhwa S. Floating microspheres of cimetidine: Formulation, characterization and in vitro evaluation. Acta Pharm 2005;55:277-85.

26. Arindam H, Biswanath S. Preparation and in vitro evaluation of polystyrene coated microcapsule of drug-resin complex for achieving prolonged release of diltiazem hydrochloride. AAPS PharmSciTech 2006;7 Suppl 2:34-49.

27. Tayade PT, Kale RD. Encapsulation of water-insoluble drug by a cross-linking technique: Effect of process and formulation variables on encapsulation efficiency, particle size, and in vitro dissolution rate. AAPS PharmSci 2004;6:E12

28. Raslan HK, Maswadeh H. In vitro dissolution kinetic study of theophyline from mixed controlled release matrix containing HPMC and glycerylbehenate. Indian J Pharm Sci 2006;68:308-12.

29. Augustijns P. In vitro dissolution models for prediction of in vivo performance of oral dosage forms. Eur J Pharm Sci 2014;57:342-66

30. Eudragit L100/L100-55 Technical Literature-Evonik Industries. Available 
from: http://www.eudragit.evonik.com/sites/dc/Downloadcenter/Evonik/ Product/Eudragit/Eudragitß\%20Products.pdf. [Last accessed on 2010].

31. Missaghi S, Young C, Fegely K, Rajabi-Siahboomi AR. Delayed release film coating applications on oral solid dosage forms of proton pump inhibitors: Case studies. Drug Dev Ind Pharm 2010;36:180-9.

32. Swamykannu DM, Gupta VR, Yasam H. Nonaqueous enteric coating application of HPMC and Eudragit L100 on hard gelatin capsules: Designed to achieve intestinal delivery. J App Pharm Sci 2015;5:1-6.

33. EUDRAGIT ${ }^{\circledR}$ Acrylic Polymers for Solid Oral Dosage Forms. Available from: http://www.rofarma.com/allegati/97.pdf. [Last accessed on 2015 Feb 02].

34. Matteucci ME, Paguio JC, Miller MA, Williams RO $3^{\text {rd }}$, Johnston KP. Highly supersaturated solutions from dissolution of amorphous itraconazole microparticles at pH 6.8. Mol Pharm 2009;6: 375-85.

35. Kiliçarslan M, Baykara T. The effect of the drug/polymer ratio on the properties of the verapamil $\mathrm{HCl}$ loaded microspheres. Int $\mathrm{J}$ Pharm 2003;252:99-109.

36. Patwekar SL, Baramade MK. Controlled release approach to novel multiparticulate drug delivery system. Int J Pharm Pharm Sci 2012;4:757-63.

37. Redfern PH, Lemmer B. Physiology and Pharmacology of Biological Rhythms. New York: Springer Science \& Business Media; 2014.

38. Malladi M, Jukanti R. Floating pulsatile drug delivery system of famotidine: Design, statistical optimization, and in vitro evaluation. Int J Pharm Pharm Sci 2016;8:169-81.

39. Singh S, Arora S, Neelam, Allawadi D. Formulation, optimization and evaluation of sustained release microspheres using Taguchi design. J Pharm Technol Res Manage 2014;2 Suppl 1:253-64.

40. Patil CC, Joshi AS, Shiralashetti SS. Design, characterization and evaluation of Eudragit microspheres containing glipizide. Drug Invent Today 2013;5:229-34 